University of Nebraska - Lincoln

DigitalCommons@University of Nebraska - Lincoln

Uniformed Services University of the Health

Sciences

U.S. Department of Defense

1990

\title{
Raman Spectroscopy of Synthetic Antimicrobial Frog Peptides Magainin 2a and PGLa
}

\author{
Robert W. Williams \\ Uniformed Services University of the Health Sciences, rwilliams@uthsc.edu \\ Ruth Starman \\ Uniformed Services University of the Health Sciences \\ Kenneth M. P. Taylor \\ Uniformed Services University of the Health Sciences \\ Kenneth Gable \\ Uniformed Services University of the Health Sciences \\ Troy Beeler \\ Uniformed Services University of the Health Sciences \\ See next page for additional authors
}

Follow this and additional works at: https://digitalcommons.unl.edu/usuhs

Part of the Medicine and Health Sciences Commons

Williams, Robert W.; Starman, Ruth; Taylor, Kenneth M. P.; Gable, Kenneth; Beeler, Troy; Zasloff, Michael; and Covell, David, "Raman Spectroscopy of Synthetic Antimicrobial Frog Peptides Magainin 2a and PGLa" (1990). Uniformed Services University of the Health Sciences. 34.

https://digitalcommons.unl.edu/usuhs/34

This Article is brought to you for free and open access by the U.S. Department of Defense at DigitalCommons@University of Nebraska - Lincoln. It has been accepted for inclusion in Uniformed Services University of the Health Sciences by an authorized administrator of DigitalCommons@University of Nebraska Lincoln. 


\section{Authors}

Robert W. Williams, Ruth Starman, Kenneth M. P. Taylor, Kenneth Gable, Troy Beeler, Michael Zasloff, and David Covell 


\title{
Raman Spectroscopy of Synthetic Antimicrobial Frog Peptides Magainin 2a and $\mathrm{PGLa}^{\dagger}$
}

\author{
Robert W. Williams, ${ }^{*, \ddagger}$ Ruth Starman, ${ }^{\ddagger}$ Kenneth M. P. Taylor, ${ }^{\ddagger}$ Kenneth Gable, ${ }^{\ddagger}$ Troy Beeler,${ }^{\ddagger}$ Michael Zasloff, ${ }^{\$}$ \\ and David Covell" \\ Department of Biochemistry, Uniformed Services University of the Health Sciences, Bethesda, Maryland 20814, and Department \\ of Mathematical Biology and Human Genetics Branch, National Institute of Child Health and Human Development, National \\ Institutes of Health, Bethesda, Maryland 20892 \\ Received September 18, 1989; Revised Manuscript Received December 5, 1989
}

\begin{abstract}
Magainin and PGLa are 23- and 21-residue peptides isolated from the skin of the African clawed frog Xenopus laevis. They protect the frog from infection and exhibit a broad-spectrum antimicrobial activity in vitro. The mechanism of this activity involves the interaction of magainin with microbial membranes. We have measured the secondary structure and membrane-perturbing ability of these peptides to obtain information about this mechanism. Our results show that mgn2a forms a helix with an average length of less than $20 \AA$ upon binding to liposomes. At high concentrations $(50 \mathrm{mg} / \mathrm{mL}) \mathrm{mgn} 2 \mathrm{a}$ spontaneously solubilizes phosphatidylcholine liposomes at temperatures above the gel-liquid-crystalline phase transition. Mgn2a appears to bind to the surface of liposomes made of negatively charged lipids without spontaneously penetrating the bilayer. Finally, mgn2a and PGLa interact together with liposomes in a synergistic way that enhances the helix content of one or both of the peptides and allows the peptides to more easily penetrate the bilayer. PGLa mixed with a small nonperturbing amount of magainin 2 amide is $25-43$ times as potent as PGLa alone at inducing the release of carboxyfluorescein from liposomes. The results suggest that the mechanism of antimicrobial activity does not involve a channel formed by transmembrane helical peptides.
\end{abstract}

$\mathbf{M}$ againin, also known as PGS ${ }^{1}$ (Giovannini et al., 1987; Terry et al., 1988), is a family of 23-residue peptides that are secreted from the skin of the African clawed frog. They protect the frog from wound infection and exhibit a broadspectrum antimicrobial activity in vitro (Zasloff, 1987; Zasloff et al., 1988). On a molar basis this activity is as potent as tetracycline against some organisms.

PGLa, another antimicrobial peptide isolated from frog skin, has an antimicrobial activity that is comparable to that of magainin 2 (Soravia et al., 1988), but these peptides have little sequence homology. The sequences of magainin 1 amide (mgn la), magainin 2 amide (mgn2a), and PGLa are (Giovannini et al., 1987)

mgn 1a: Gly-Ile-Gly-Lys-Phe-Leu-His-Ser-Ala-Gly-LysPhe-Gly-Lys-Ala-Phe-Val-Gly-Glu-Ile-Met-Lys-Ser- $\mathrm{NH}_{2}$ mgn2a: Gly-Ile-Gly-Lys-Phe-Leu-His-Ser-Ala-Lys-LysPhe-Gly-Lys-Ala-Phe-Val-Gly-Glu-Ile-Met-Asn-Ser- $\mathrm{NH}_{2}$ PGLa: Gly-Met-Ala-Ser-Lys-Ala-Gly-Ala-Ile-AlaGly-Lys-Ile-Ala-Lys-Val-Ala-Leu-Lys-Ala-Leu- $\mathrm{NH}_{2}$

These peptides are positively charged and can form extremely amphiphilic helices about $30 \AA$ in length. These features are common to polypeptides that bind to and effect the permeability of lipid bilayers (Sparrow \& Goto, 1982; DeGrado et al., 1981; Green et al., 1987), and it has been suggested that

\footnotetext{
${ }^{\dagger}$ This work was funded in part by the Strategic Defense Initiative Organization Medical Free Electron Laser Program (at USUHS: Medical Applications of Laser Technology Project Grant GM7160). The opinions or assertions contained herein are the private ones of the authors and are not to be construed as official or reflecting the views of the Department of Defense or the Uniformed Services University of the Health Sciences.

* Address correspondence to this author.

*Uniformed Services University of the Health Sciences.

'Human Genetics Branch, NIH.

" Department of Mathematical Biology, NIH.
}

magainins might act as detergents or transmembrane helical channel formers (Zasloff, 1987; Guy \& Raghunathan, 1988).

Indeed, measurements using a single channel conductance apparatus indicate that magainin forms a voltage-dependent channel in artificial membranes (Cruciani et al., 1988). Magainin 2 amide causes membrane depolarization in Escherichia coli cells and cytochrome oxidase liposomes (Juretic et al., 1989), and magainin 2 amide and PGLa dissipate the electric potential across energy-transducing membranes, uncoupling respiration from other free-energy-requiring processes (Westerhoff et al., 1989a,b). The effect of mgnl on the permeability of liposomes has been investigated by Matsuzaki et al. (1989), who observe that mgnl induces leakage of calcein out of negatively charged vesicles and binds to bovine brain phosphatidylserine according to the Langmuir isotherm with a binding constant of $43.8 \times 10^{5} / \mathrm{M}$ and that leakage appears to occur at a binding number of 0.03 per lipid molecule; their $\mathrm{CD}$ measurements indicate that mgnl has an unordered structure in solution and that it forms a $57 \% \alpha$-helix upon binding to PS.

CD of peptide in $40 \%$ trifluoroethanol (TFE; mixtures of water and TFE are used as a membrane mimetic solvent) indicates $24 \% \alpha$-helix (Chen et al., 1988), and NMR of 30 $\mathrm{mg} / \mathrm{mL}$ mgn $2 \mathrm{a}$ in $25 \%$ TFE indicates some $\alpha$-helix (Marion et al., 1988). Raman measurements show that liposome-bound mgn2a contains as much as $71 \%$ helix (Williams et al., $1988 \mathrm{a}, \mathrm{b})$. These studies also indicate that magainin 2 amide

\footnotetext{
${ }^{1}$ Abbreviations: mgn 1, magainin $1 ;$ mgn2, magainin $2 ;$ mgn2a and magainin 2a, magainin 2 amide; PGS, peptide beginning with glycine and ending with serine; PGLa, peptide beginning with glycine and ending with leucine amide; SDS, sodium dodecyl sulfate; DPPG, L- $\alpha$-dipalmitoylphosphatidylglycerol; DPPC, dipalmitoylphosphatidylcholine; PS, bovine brain phosphatidylserine; PC, bovine brain phosphatidylcholine; PE, bovine brain phosphatidylethanolamine; SUV, small unilamellar vesicle; $\mathrm{MLV}$, multilamellar vesicle; $\mathrm{Gdn} \cdot \mathrm{HCl}$, guanidine hydrochloride; TFE, 2,2,2-trifluoroethanol; CF, 6-carboxyfluorescein.
} 
contains $0 \%$ helical structure in aqueous solutions.

To ascertain the effect of secondary structure on antimicrobial activity, Chen et al. (1988) prepared a series of magainin analogues with varying propensities to form helix and determined the dose-response to these compounds in biological assays. By substituting residues 9,13 , and 18 with D-alanines, they prepared a derivative that is unlikely to form a helix. By substituting glycines 13 and 18 with L-alanine, they increased the helix-forming tendency of the peptide. The results showed a positive correlation between antimicrobial activity and tendency to form helix in TFE. Raman measurements of secondary structure of these analogues bound to liposomes also show this correlation (Williams et al., 1988c). Omission of glycine 18 in mgn2a does not increase antimicrobial activity, but does increase hemolytic activity (Cuervo et al., 1988).

In this paper we survey the secondary structure and membrane-perturbing characteristics of mgn $2 a$ and PGLa bound to liposomes under a variety of conditions. We measure the effect of mgn2a binding on the structure of liposome acyl chains, and we quantitate the membrane-perturbing kinetics of mgn2a and PGLa by measuring CF release from CF-loaded liposomes. Our results show that mgn2a forms an $\alpha$-helix with an average length of less than $20 \AA$ upon binding to liposomes. At high concentrations $(50 \mathrm{mg} / \mathrm{mL}) \mathrm{mgn} 2 \mathrm{a}$ spontaneously solubilizes phosphatidylcholine liposomes at temperatures above the gel-liquid-crystalline phase transition. Mgn2a appears to bind to the surface of liposomes made of negatively charged lipids without spontaneously penetrating the bilayer. Finally, mgn2a and PGLa interact together with liposomes in a synergistic way that enhances the helix content of one or both of the peptides and facilitates the peptide's penetration into the bilayer.

\section{Materials and Methods}

Materials. The purification of magainin $2 \mathrm{a}$ and PGLa is described elsewhere (Zasloff, 1987). Melittin was obtained from Sigma and further purified by reversed-phase highpressure liquid chromatography on a Waters $8 \mathrm{MBC} 1810$ Radial-Pak C-18 cartridge. Initial gradient conditions were $70 \%$ trifluoroacetic acid and $30 \%$ acetonitrile, changing to $40 \%$ trifluoroacetic acid and $60 \%$ acetonitrile over $30 \mathrm{~min}$ at a flow rate of $2 \mathrm{~mL} / \mathrm{min}$. Synthetic DPPG and DPPC and bovine brain PC, PE, and PS were obtained from Avanti Polar Lipids Inc., Pelham AL.

Liposome Preparation. DPPG and DPPC in multilamellar vesicles (MLVs) were prepared as follows: A solution of lipid in chloroform was evaporated to dryness in a test tube under a stream of nitrogen. Then $0.14 \mathrm{M} \mathrm{KCl}$ was added to bring the final lipid concentration to $10-50 \mathrm{mg} / \mathrm{mL}$. This dispersion was subjected to 10 cycles of vortexing, freezing in dry iceacetone, and thawing to $50^{\circ} \mathrm{C}$. Lipid-bound and unbound peptide could be rapidly and completely separated by pelleting the vesicles in a microhematocrit centrifuge.

Small unilamellar vesicles (SUVs) for CF release experiments were prepared as follows: $5 \mathrm{mg} / \mathrm{mL}$ phospholipid (2:5:3 PC:PE:PS) was evaporated to dryness in a test tube under a stream of nitrogen and sonicated in a solution of $0.5 \mathrm{M} \mathrm{NaCl}$, $10 \mathrm{mM}$ Pipes, pH 7.0, and $80 \mathrm{mM} \mathrm{CF}$ (Kodak) by using a Heat Systems-Ultrasonics Inc. Model W185F sonicator with a cup-horn bath at maximum power for $20 \mathrm{~min}$. These CFloaded vesicles were separated from free $C F$ by elution through a 2-mL Sephadex G25 column with $0.5 \mathrm{M} \mathrm{NaCl}$ and $10 \mathrm{mM}$ Pipes, $\mathrm{pH}$ 7.0. The void volume was collected and diluted to a lipid concentration of $2.5 \mathrm{mg} / \mathrm{mL}$ for storage. These vesicles were diluted to a concentration of $50 \mu \mathrm{g} / \mathrm{mL}$ lipid in $0.5 \mathrm{M}$ $\mathrm{NaCl}$ and $10 \mathrm{mM}$ Pipes. Aliquots $(1 \mathrm{~mL})$ of this dispersion were used to measure CF release. Increase in fluorescence was measured at $520 \mathrm{~nm}$ with $470-\mathrm{nm}$ excitation (Weinstein et al., 1984); 100\% fluorescence was determined by the addition of $20 \mu \mathrm{L}$ of $10 \%$ Triton X-100, to a final concentration of $0.5 \%$ Triton.

Magainin 2 amide, PGLa, and melittin solutions were prepared to $5 \% \mathrm{w} / \mathrm{w}$ in $0.14 \mathrm{M} \mathrm{NaCl}$, and the $\mathrm{pH}$ values of these solutions were adjusted to 7.4 with $0.1 \mathrm{M} \mathrm{NaOH}$. The formula weights (including neutralizing salts) of mgn2a and PGLa were taken to be 2701 and 2146, respectively. Peptide-lipid complexes were prepared by mixing $10 \mu \mathrm{L}$ of peptide solution with $10 \mu \mathrm{L}$ of lipid suspension. Samples were pelleted in melting point capillary tubes with a Damon/IEC microhematocrit centrifuge for $15 \mathrm{~min}$ to concentrate the lipidpeptide complex and to exclude supernatant containing unbound peptide. Spectra were collected of the pellets and supernatants of these samples. The pellets were then resuspended in their respective supernatants and heated at $50{ }^{\circ} \mathrm{C}$; the magainin-DPPG sample was heated for $30 \mathrm{~min}$, and the melittin-DPPG sample was heated for $10 \mathrm{~min}$. After $10 \mathrm{~min}$ of heating, the milklike lipid dispersion in the melittin sample became mostly clear, indicating that large liposomes had been broken into much smaller particles. Spectra were collected again. Another $20 \mu \mathrm{L}$ of DPPG suspension was added to the magainin and melittin, the pellets were resuspended, the samples were heated at $50^{\circ} \mathrm{C}$ for $30 \mathrm{~min}$, and spectra were collected again.

Raman Spectroscopy. Raman instrumentation is described elsewhere (Williams, 1986). The laser was operated at 514.5 $\mathrm{nm}$ with typically $200 \mathrm{~mW}$ of light power focused at the sample to a beam with a diameter of about $0.5 \mathrm{~mm}$ for precipitates of lipid and peptide, and a diameter of about $0.1 \mathrm{~mm}$ for solutions and supernatants. The thermostated sample holder was held at $14^{\circ} \mathrm{C}$.

Raman spectra of peptides were analyzed for secondary structure information according to the method of Williams $(1983,1986)$. Briefly, fractions of helix, $\beta$-strand, reverse turn, and unfolded structure are estimated from the Raman spectrum of the peptide by fitting the amide I spectrum with a linear combination of amide I spectra of proteins whose structures are known by X-ray diffraction. The secondary structure is then calculated as a sum of fractions of the reference proteins. The procedure used here differs from the one described (Williams, 1986) in that the spectrum of lysozyme in $4 \mathrm{M}$ guanidine hydrochloride $(\mathrm{Gdn} \cdot \mathrm{HCl}$ ) was added to the set of reference spectra. This amide I spectrum is identical with the spectra of several other proteins in unfolding concentrations of $\mathrm{Gdn} \cdot \mathrm{HCl}$ and is taken here to represent the spectrum of a protein or peptide that is unfolded.

Subtraction of the spectrum of water from spectra of peptide-lipid mixtures cannot be performed by the method described earlier (Williams, 1986) because of the strong phospholipid ester $\mathrm{C}=\mathrm{O}$ stretching band between 1700 and 1780 $\mathrm{cm}^{-1}$. The correct amount of water spectrum to be subtracted was determined as follows: After collection of Raman spectra of the pelleted vesicles, the pellet was evaporated to dryness under a stream of nitrogen and the Raman spectrum of the dry pellet collected. (This drying treatment does not completely dehydrate liposome samples.) Water subtraction was adjusted to bring the water-subtracted spectrum into congruence with the dehydrated sample spectrum. These spectra were generally identical.

We define here a new expression for a lipid order parameter (LOP) to quantitate the effect of peptides on the structure of phospholipids 


$$
\mathrm{LOP}=\frac{\frac{I_{1128, \mathrm{GP} \text { sample }}}{I_{1095, \mathrm{GP} \text { sample }}}-\frac{I_{1125, \mathrm{LCP} \text { reference }}}{I_{1095, \mathrm{LCP} \text { reference }}}}{\frac{I_{1128, \mathrm{GP} \text { reference }}}{I_{1095, \mathrm{GP} \text { reference }}}-\frac{I_{1125, \mathrm{LCP} \text { reference }}}{I_{1095, \mathrm{LCP} \text { reference }}}}
$$

where $I_{1128}$ is the Raman intensity at $1128 \mathrm{~cm}^{-1}$ and the GP reference is the spectrum of gel-phase (GP) multilamellar lipid vesicles (MLVs) prepared by freezing and thawing in normal saline. The spectrum is measured at a temperature $\left(14^{\circ} \mathrm{C}\right.$ in this case) well below both the main and premelting gel to liquid-crystalline phase (LCP) transitions. The LCP reference is the spectrum of the same vesicles measured at a temperature $\left(50^{\circ} \mathrm{C}\right.$ for DPPG) well above the main GP to LCP transition. The intensity at $1095 \mathrm{~cm}^{-1}$ is an iso-Raman point for the melting transition (Gaber et al., 1978) and is used to normalize each spectrum.

This parameter (LOP) indicates the intensity of the 1128$\mathrm{cm}^{-1}$ band (which is due to coupled vibrations from adjacent trans bonds) relative to its intensity in nearly all trans structures (solid), where LOP $=1$, and all melted structures, where LOP $=0$. This band is generally accepted to be the most reliable indicator of this structure change. We cannot presently explain the changes observed in the $1064-\mathrm{cm}^{-1}$ band. The $1128-\mathrm{cm}^{-1}$ band does not indicate the number of gauche and trans bonds, since the intensity of these bands is probably not a linear function of conformation. Nor does it indicate to what extent the peptide is or is not inserted into the acyl-chain region of the bilayer. It does, however, give a relative indication of how peptide binding disrupts (or orders) the lipid acyl-chain structure.

Analysis of CF Release. CF fluorescence data were converted to percent $C F$ remaining in vesicles by the expression $\% C F_{\text {rem }}=\left(1-F / F_{\mathrm{T}}\right) / Q_{\mathrm{v}}$, where $F$ is fluorescence measured at any time, $F_{\mathrm{T}}$ is total $\mathrm{CF}$ fluorescence after disruption of vesicles with Triton, and $Q_{v}$ is a correction for the residual fluorescence of dye in the vesicles (Weinstein et al., 1984). To quantitate differences between the membrane-perturbing abilities of PGLa and a mixture of PGLa and mgn2a, a double-exponential fit was applied to the CF release data by using the SAAM (Simulation, Analysis And Modeling) program (Berman \& Weiss, 1978). CF remaining in liposomes was expressed as $C F_{\text {rem }}(\%)=A e^{k_{1} t}+B e^{k_{2} t}$, where $A$ and $B$ are proportionality coefficients with $A+B=100, t$ is time, and $k_{1}$ and $k_{2}$ are pseudo-first-order rate constants where $k_{1}=$ $K_{1}$ [peptide] $+C$ and $k_{2}=K_{2}$ [peptide] $+C$. Constants for liposome permeability, $K_{1}$ and $K_{2}$, were estimated as the slope of the linear regression line through $k_{1}$ and $k_{2}$ plotted as a function of peptide concentration (Figure 5). For example, for PGLa alone, $K_{1}=\Delta k_{1} / \Delta[\mathrm{PGLa}]=0.16(\mathrm{~s} \cdot \mathrm{M})^{-1}$. There are a number of ways to analyze this type of kinetic data (Bentz et al., 1988; Bentz \& Nir, 1981). We have chosen the presentation described here to emphasize the differences between the effects of each isolated peptide and a mixture of mgn $2 a$ and PGLa.

\section{RESULTS AND DISCUSSION}

$\alpha$-Helical Peptides. Figure 1 shows the Raman amide I spectra of magainin 2 amide (mgn2a) compared with spectra of other peptides and proteins with known structures. One of these structures is that of melittin, a 26-residue amphipathic peptide that is $96 \%$ helix in the crystal (Terwilliger et al., 1982). We compare spectra of mgn2a to those of melittin because melittin is similar in some ways to mgn2a in size, charge, and amphipathicity and because much is already
Table I: Secondary Structure Content ${ }^{a}$ (Percent) in Magainin 2a and PGLa from the Raman Amide I Spectrum

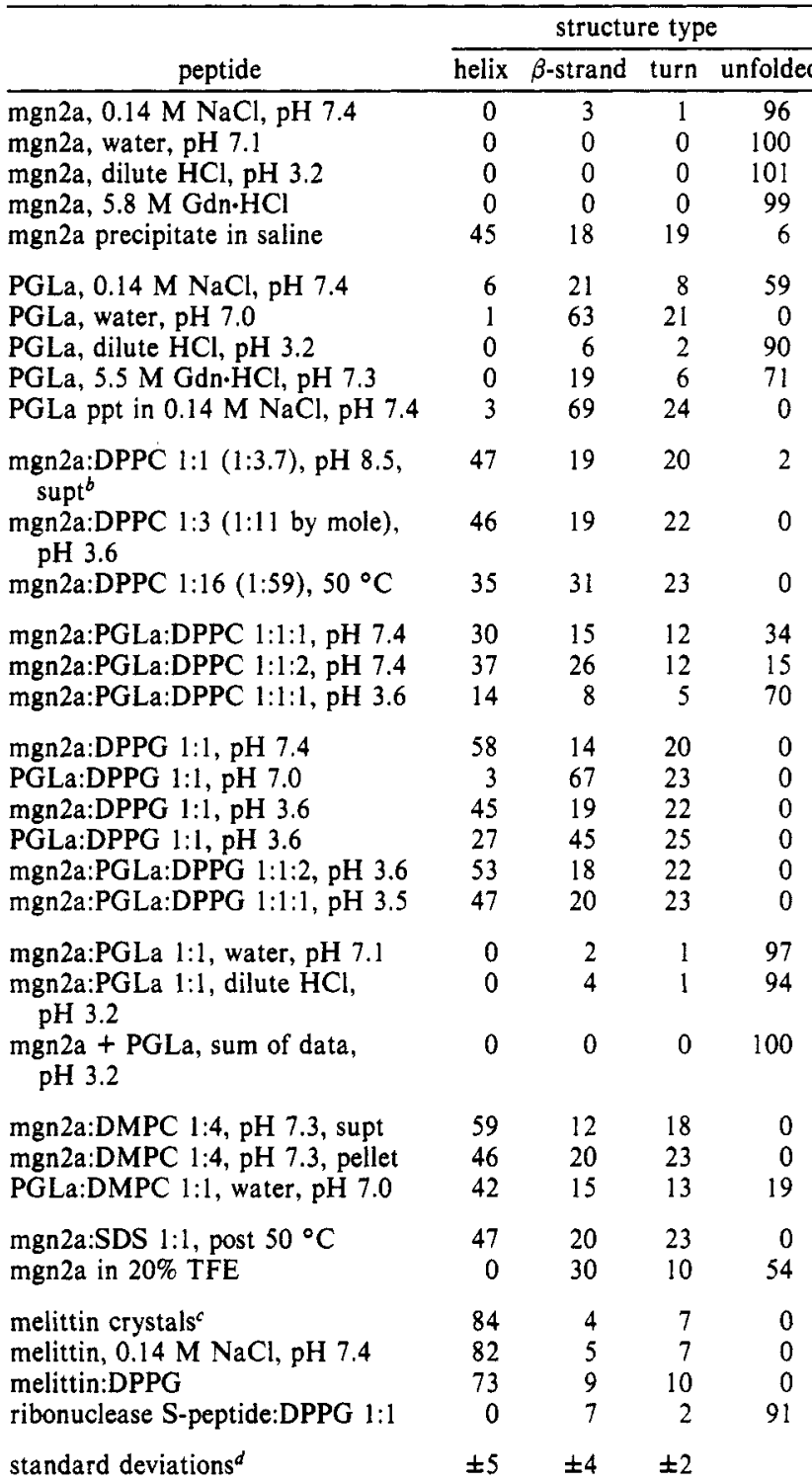

${ }^{a}$ The sum of structure contents was $100 \pm 2 \%$. Undefined structure content, the remainder from $100 \%$, is not shown. Standard deviations represent differences between Raman and X-ray diffraction measurements for the reference proteins. ${ }^{b}$ "supt" indicates that liposomes were dissolved by peptide and that the spectrum was taken of the clear supernatant above pelleted material. "Melittin, having a $96 \%$ helical crystal structure, was excluded from the reference set for this calculation. Melittin was not excluded from the reference set for estimates of its structure in DPPG and $0.14 \mathrm{M} \mathrm{NaCl}$.

known about the structure of melittin and its interaction with lipid bilayers (Brown et al., 1982; Bernard et al., 1982; Georghiou et al., 1982; DeGrado et al., 1982; Levin et al., 1982). In addition, there is an error in the Raman estimate of helix content in melittin that may also exist in the estimate for helical mgn2a samples; the Raman estimate of helix content in melittin crystals (Table I) is $84 \%$, which is $12 \%$ (three residues) below the $\mathrm{X}$-ray diffraction structure. This difference may be due to end effects, since the ends of helical segments have an amide I spectrum different from that of residues in the middle of a helical segment (Williams \& Dunker, 1981). We suspect that helical residues that are on the very ends of a peptide (as they are in melittin) will have yet a different amide I spectrum. Our estimate of helix content for mgn2a in DPPG here is $58 \%$ (Table I). If we assume that 


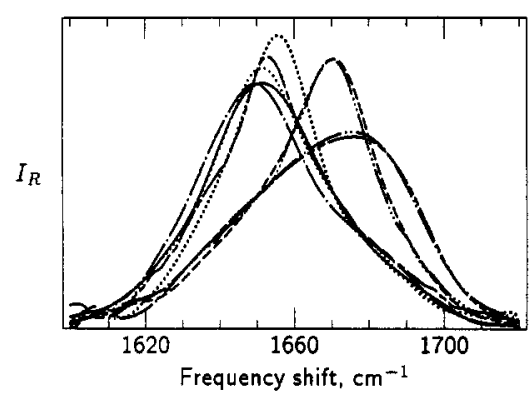

FIGURE 1: Amide I Raman spectrum of magainin 2 amide bound to DPPG liposomes, compared with reference spectra of peptides and proteins with known structures. Mgn2a:DPPG 1:1 (ratios are by weight) in saline, $\mathrm{pH} 7.4$ (heavy dotted line); melittin crystals, $>96 \%$ helix (light dotted line); melittin:DPPG 1:1 in saline, $\mathrm{pH} 7.4$ (solid line); melittin in saline, pH 7.4 (line with one dot); hemerythrin, $80 \%$ helix in a four-helix bundle (line with one dash); concanavalin $A$ crystals, $65 \% \beta$-sheet $-2 \%$ helix (dashed line); erabutoxin, $62 \% \beta$ sheet $-0 \%$ helix (line with three dots); unfolded ribonuclease S-peptide (thin line with two dots); lysozyme unfolded in $4 \mathrm{M}$ guanidine hydrochloride (line with two dashes).

this estimate is also $12 \%$ low, we can set an upper limit of $70 \%$ helix for the average helix content in this sample of mgn2a. This corresponds to 16 residues, $24 \AA$ in an $\alpha$-helix, which is not long enough to span a lipid bilayer.

The spectrum of a helical peptide bound to lipid vesicles or in solutions may be different from the spectrum of the same peptide, with the same structure, in a crystal. To investigate this possibility in the context of helical peptides that may form bundles that span lipid bilayers, we collected Raman spectra of melittin bound to lipid vesicles and in solution. As can be seen in Figure 1, the differences between the spectra of crystal and lipid-bound structures are relatively small.

We show in Figure 1 the spectra of proteins and peptides that illustrate the validity of using a database of Raman spectra of relatively large proteins for an analysis of the spectra of a 23-residue peptide. Erabutoxin has 62 residues, $3 \mathrm{di}$ sulfides, and is $50 \% \beta$-sheet-0\% helix (Low et al., 1976). Concanavalin A has 237 residues, contains no cysteines, and is $51 \% \beta$-sheet-2\% helix (Reeke et al., 1975). The secondary structure contents and the amide I spectra of these proteins are nearly identical. The spectrum of hemerythrin, a 113residue $80 \%$ helical protein, is similar to the spectra of melittin, differing only in the way expected for two helical proteins that differ in helix content. The amide I spectrum of the 24-residue ribonuclease S-peptide in its unfolded structure (Kim et al., 1982) is nearly identical with the spectrum of lysozyme in guanidine hydrochloride, indicating that it is valid to use this spectrum of lysozyme as a reference for unfolded structure. There is no indication that secondary structure in a 20-residue peptide will have an amide I spectrum that is different from the same secondary structure in a large protein.

Interaction with Liposomes. The interactions of mgn2a with negatively charged DPPG and with zwitterionic DPPC and DMPC vesicles are different. When mgn2a was added to dispersions of DPPG MLVs, the vesicles rapidly flocculated. The flocculated appearance of these samples remained unchanged when they were heated to a temperature above the gel to liquid-crystalline phase transition. These aggregated vesicle-peptide complexes were easily separated from free mgn2a that might be left in the solution. We observed a marked change in the light scattering from lipid dispersions upon addition of peptides. Since we have no quantitative light-scattering measurements from these samples, some of them only $5 \mu \mathrm{L}$, we describe this change qualitatively here by comparing the appearance of the dispersion to milk, where light

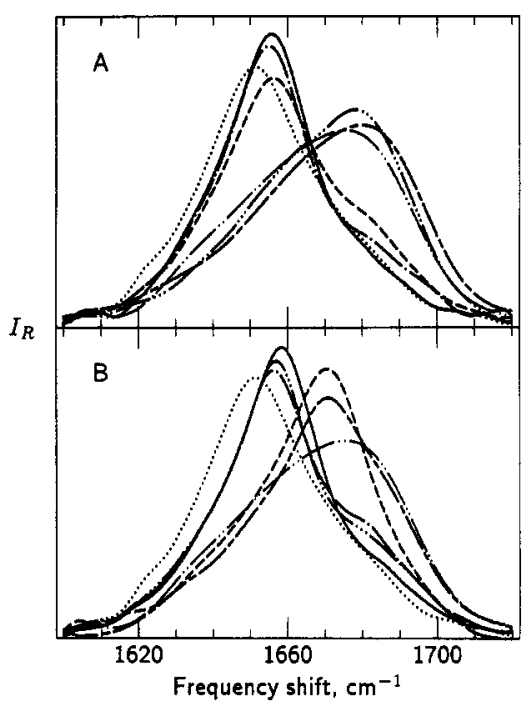

FIGURE 2: Amide I Raman spectrum of magainin 2 amide bound to liposomes and in solution. The spectra of melittin crystals (dotted line) and of unfolded ribonuclease S-peptide (thin line with two dots) are shown in both panels as references. (A) Mgn2a:DPPG 1:1 (ratios are by weight) in saline, pH 7.4 (solid line); mgn2a:DMPC 1:4 in water, $\mathrm{pH} 7.3$ (line with one dot); $\mathrm{mgn} 2 \mathrm{a} 200 \mathrm{mg} / \mathrm{mL}$ in $5.8 \mathrm{M}$ $\mathrm{Gdn} \cdot \mathrm{HCl}, \mathrm{pH} 7$ (line with one dash); mgn2a precipitated at $14^{\circ} \mathrm{C}$ in saline, $\mathrm{pH} 7.4$ (dashed line); mgn2a in saline solution at $22^{\circ} \mathrm{C}$, pH 7.4 (line with three dots). (B) Mgn2a:DPPC 1:3 in saline, $\mathrm{pH}$ 3.6 , after $50^{\circ} \mathrm{C}, 15 \mathrm{~min}$, clear dispersion (line with three dots); mgn2a:DPPC 1:1 pH 8.5, after $50^{\circ} \mathrm{C}, 30 \mathrm{~s}$, clear dispersion (line with one dot); mgn2a:SDS $1: 1.5$ after $50^{\circ} \mathrm{C}, 30 \mathrm{~s}$, clear solution (solid line); mgn $2 a$ in $20 \%$ TFE in water (line with one dash); concanavalin A crystals, a $55 \% \beta$-sheet $-2 \%$ helix reference protein (dashed line).

scattering is very high, before addition of peptide, and as becoming clear (as water) after addition. When mgn2a was added to the milky dispersions of DPPC and DMPC, no change was observed. However, when these samples were heated to a temperature above the gel to liquid-crystalline phase transition, they immediately became clear, indicating that the liposomes were solubilized into much smaller particles. The interactions of melittin with both DPPG and DPPC were more similar; the milky vesicle dispersion became nearly clear in both cases, even to some extent at temperatures below the gel to liquid-crystalline phase transitions. They were not as clear as those obtained from mgn2a in DPPC and DMPC.

The structure of mgn2a changes upon binding to lipid vesicles from a mostly unfolded structure in aqueous solution to a helical structure in the peptide-lipid complex (Figure 2; Table I). The amide I spectra of mgn2a in aqueous solutions or in $\mathrm{Gdn} \cdot \mathrm{HCl}$ are to some extent different from our reference spectrum for unfolded peptide structure (Figure 2A). This may indicate that, while being mostly unfolded, the peptide has some preferred turn structure in solution, and there may be some artifact from the subtraction of the $\mathrm{Gdn} \cdot \mathrm{HCl} \mathrm{spec-}$ trum. The structure of mgn2a appears to be similar bound to DPPG and DMPC (Figure 2A; Table I), but helix content is lower in DPPC by more than 10\% (two residues). The mgn2a structures in the form precipitated from aqueous solution in the cold (Figure 2A) and in DPPC (Figure 2B) are similar.

The ratio of lipid to peptide may affect peptide structure, especially in mixtures of mgn2a and DPPC where vesicles are solubilized by the peptide and free peptide cannot be separated from the peptide-lipid complex. To test this possibility, samples of Mgn2a-DPPC were measured at mole ratios of 1:3.7, 1:11, and 1:59. At the 1:59 ratio the dispersion retained much of its turbid appearance after the addition of peptide and incubation at $50^{\circ} \mathrm{C}$. The mgn2a structure did not change 


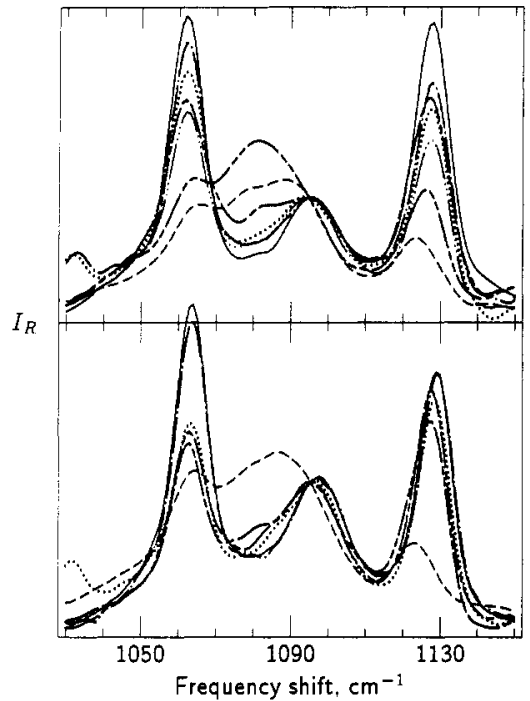

FIGURE 3: Raman spectra of pellets of lipid LUVs in PBS (unless otherwise indicated) with and without bound peptide, showing the lipid acyl-chain $\mathrm{C}-\mathrm{C}$ stretching region, and in particular the band at $1128 \mathrm{~cm}^{-1}$, that indicates (nonlinearly) the extent of trans-gauche isomerization. The top frame shows spectra of DPPG well below the gel to liquid-crystalline phase transition at $14^{\circ} \mathrm{C}$ (thin solid line) and of DPPG just above this transition, at $45^{\circ} \mathrm{C}$ (thin dashed line); mgn2a:DPPG $1: 1$ at $14^{\circ} \mathrm{C}, \mathrm{pH} 7.4$ (the band at 1032 is from the mgn2a phenylalanines) (line with one dot); mgn2a:DPPG 1:1 at 14 ${ }^{\circ} \mathrm{C}, \mathrm{pH} 7.4$, after $30 \mathrm{~min}$ at $50^{\circ} \mathrm{C}$ (dotted line); melittin:DPPG $1: 1$ at $14^{\circ} \mathrm{C}, \mathrm{pH} 7.4$ (line with one dash); melittin:DPPG $1: 1$ at $14^{\circ} \mathrm{C}$,

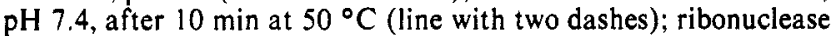
S-peptide:DPPG $1: 1$ at $14^{\circ} \mathrm{C}$, pH 7.4 , after $30 \mathrm{~min}$ at $50^{\circ} \mathrm{C}$ (this spectrum is the same before the $50{ }^{\circ} \mathrm{C}$ treatment) showing that ribonuclease $\mathrm{S}$-peptide in an unfolded structure disrupts the lipid acyl-chain structure more than mgn2a (thin line with three dots). (Bottom frame) DPPC at $14^{\circ} \mathrm{C}$ (thin solid line); DPPC at $45^{\circ} \mathrm{C}$ (thin dashed line); mgn2a:DPPC $1: 1$ at $14^{\circ} \mathrm{C}, \mathrm{pH} 3.7$, showing that mgn2a does not copellet with DPPC liposomes (line with one dot); mgn2a:DPPC $1: 1$ at $14^{\circ} \mathrm{C}, \mathrm{pH} 8.5$, after $10 \mathrm{~min}$ at $50^{\circ} \mathrm{C}$ (liposomes are dissolved by this treatment; this spectrum was taken of a clear solution) (dotted line); melittin:DPPC $1: 1$ at $14^{\circ} \mathrm{C}, \mathrm{pH} 5.3$ (liposomes are dissolved by this treatment, but not to a clear solution as with mgn2a; this spectrum was taken of a translucent dispersion) (line with one dash); melittin:DPPC $1: 1$ at $14^{\circ} \mathrm{C}, \mathrm{pH} 5.3$, after 10 min at 50 ${ }^{\circ} \mathrm{C}$ showing that heating this mixture to above the gel to liquidcrystalline phase transition does not induce further changes in the lipid structure (line with two dashes). Ratios are by weight.

significantly as the amount of DPPC was increased (Figure 2B; Table I). Spectra collected at $50^{\circ} \mathrm{C}$ were not significantly different from spectra collected at $14^{\circ} \mathrm{C}$, as was the case with spectra collected from samples at $\mathrm{pH} 7-9$ and at $\mathrm{pH} 3-4$.

Membrane Mimetic Solvents. Spectra of mgn2a in membrane mimetic environments, mixed with SDS and in 20\% trifluoroethanol (TFE), are significantly different from spectra of the peptide mixed with lipid vesicles (Figure 2B). These results indicate that SDS and TFE may not be good model solvents for magainins in a membrane environment. Other peptides have shown "distinctly different conformations in membranes and in organic solvents" (Wallace, 1983). Raman measurements of magainin 2 amide at $50 \mathrm{mg} / \mathrm{mL}$ in $20 \%$ TFE (Table II) appear to be in conflict with the NMR results (Marion et al., 1988) that indicate mgn2a is helical in dilute TFE solutions. However, the NMR measurements were made of solutions that contained higher concentrations of TFE. Our results from magainins in TFE will be reported more fully elsewhere.

Lipid Acyl-Chain Disorder. The extent of lipid acyl-chain disorder induced by peptide binding to DPPG and DPPC was measured from the Raman spectrum in the $\mathrm{C}-\mathrm{C}$ stretching region (Figure 3 ) and quantitated in terms of our LOP (Table
Table II: Lipid Order Parameters from the C-C Stretching Raman Spectra of Peptide-Lipid Complexes

\begin{tabular}{lcc}
\hline \multicolumn{1}{c}{ complex } & pre $50^{\circ} \mathrm{C}^{a}$ & post $50^{\circ} \mathrm{C}$ \\
\hline mgn2a:DPPG 1:1, pH 7.4 & 0.73 & 0.59 \\
melittin:DPPG 1:1 & 0.65 & 0.23 \\
ribonuclease S-peptide:DPPG 1:1 & 0.46 & 0.36 \\
mgn2a:DPPC 1:1 (1:3.7), pH 8.5, supt $^{b}$ & 1.00 & 0.83 \\
melittin:DPPC 1:1 & 0.90 & 0.71 \\
\hline
\end{tabular}

${ }^{a}$ Samples were measured before and after the sample was incubated at $50^{\circ} \mathrm{C}$ for $10-30 \mathrm{~min}$. ${ }^{b}$ "supt" indicates that liposomes were dissolved by peptide and that the spectrum was taken of the clear supernatant above pelleted material.

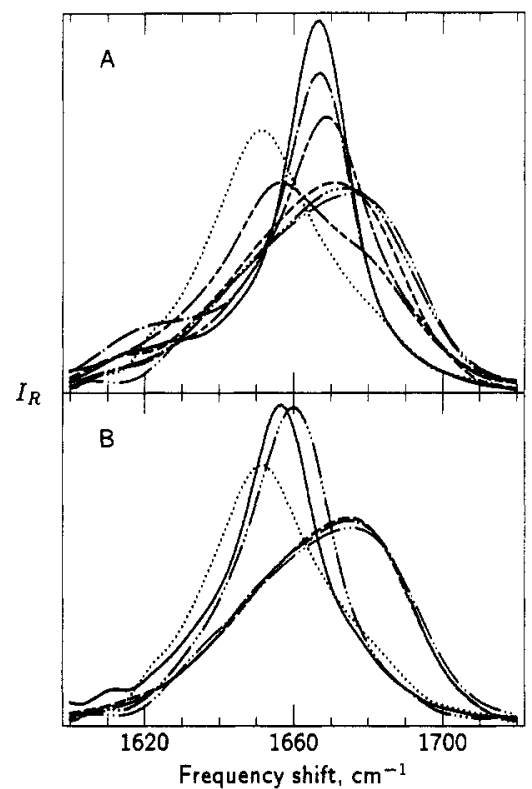

FIGURE 4: Amide I Raman spectra of PGLa and mixtures of PGLa and mgn2a bound to liposomes and in solution. The spectra of melittin crystals (dotted line) and unfolded ribonuclease $S$ peptide (line with two dots) are shown in both frames as references. (A) PGLa precipitate in $0.14 \mathrm{M} \mathrm{NaCl}, \mathrm{pH} 7.4$ (solid line); PGLa:DPPG 1:1 in dilute $\mathrm{HCl}$, pH 3.6 (line with one dot); PGLa in water $\mathrm{pH} 7.0$ (line with one dash); PGLa in water, pH 3.2 (line with three dots); PGLa in $0.14 \mathrm{M} \mathrm{NaCl}, \mathrm{pH} 7.4$ (dashed line); PGLa:DMPC 1:1, pH 7.0 (line with two dashes). (B) Mgn2a:PGLa:DPPG 1:1:2, pellet of vesicles (solid line); arithmetic sum of the spectra of mgn2a:DPPG $1: 1$ and PGLa:DPPG 1:1 (line with three dots); mgn2a:PGLa 1:1 in water, $\mathrm{pH} 7.1$ (line dot); arithmetic sum of spectra of mgn2a in saline, $\mathrm{pH}$ 7.4, and PGLa in water, $\mathrm{pH} 7.0$ (line all dash).

II). The acyl chains of DPPG appear to be slightly more disordered (contain more gauche conformations) after incubation with mgn2a at $50^{\circ} \mathrm{C}$, but the spectrum between 1000 and $1030 \mathrm{~cm}^{-1}$ (not shown) shows an increase in the intensity of the $1003-\mathrm{cm}^{-1} \mathrm{mgn} 2 \mathrm{a}$ phenylalanine band that is proportional to the decrease in the intensity of the DPPG bands upon heating. This indicates that this increase in acyl-chain disorder is probably due to an increase in the amount of mgn2a bound to the DPPG vesicles and not to a change in structure. Melittin is more disruptive than mgn2a and completely disorders the acyl chains after incubation at $50^{\circ} \mathrm{C}$, possibly by forming peptide-lipid micelles.

DPPC appears to be much less disordered by mgn2a or melittin than DPPG, even in samples of Mgn2a-DPPC complex that have turned clear after heating at $50^{\circ} \mathrm{C}$. These results, combined with our qualitative observation that mgn2a solubilizes DPPC liposomes and greatly reduces their light scattering, may indicate that the Mgn2a-DPPC complex formed after heating is a disk-shaped micelle in which the lipids can form a planar bilayer within a ring of peptide molecules. A similar annular protein-bilayer disk model has been proposed 


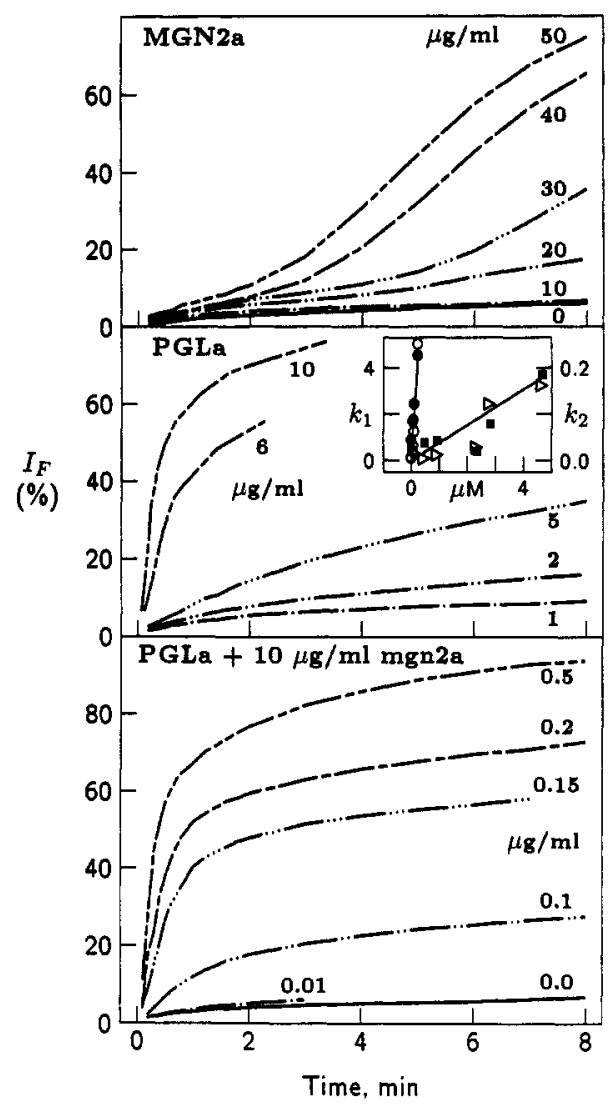

FIGURE 5: Intensity of CF fluorescence after addition of antimicrobial peptide to CF loaded liposomes. Numbers to the right, next to each curve, indicate final concentrations of peptide in micrograms per milliliter, where $10 \mu \mathrm{g} / \mathrm{mL}$ PGLa is $4.66 \mu \mathrm{M}$ and $10 \mu \mathrm{g} / \mathrm{mL} \mathrm{mgn} 2 \mathrm{a}$ is $3.7 \mu \mathrm{M}$. (Top) Magainin 2a was added at time 0. (Middle) PGLa was added at time 0 . (Inset) Pseudo-first-order rate constants (see Materials and Methods) plotted as a function of PGLa concentration. Solid symbols represent $k_{1}$, and open symbols represent $k_{2}$. PGLa $k_{1}$ (open triangle); PGLa $k_{2}$ (solid box); mixture ( $3.7 \mu \mathrm{M}$ mgn2a plus indicated amount of PGLa) $k_{1}$ (solid circle); mixture $k_{2}$ (open circle). (Bottom) Magainin 2a was added to liposomes to a final concentration of $3.7 \mu \mathrm{M} 30 \mathrm{~s}$ prior to the addition of PGLa. Time 0 indicates the addition time of PGLa. The mixture at a ratio of 1:20 PGLa to mgn2a is as active as a 23-fold higher concentration of PGLa alone.

for apolipoprotein A-I (Brouillette et al., 1982).

We added ribonuclease S-peptide to DPPG liposomes to provide a comparison of our results with mgn2a with the liposome binding behavior of another positively charged peptide of about the same size as mgn2a, but with much lower helix hydrophobic moment and fewer hydrophobic residues. Ribonuclease S-peptide copellets with DPPG liposomes in an unfolded or random structure (Table I) and disrupts the lipid acyl chains of gel-phase DPPG more than either mgn2a or melittin. Because the S-peptide is not helical in this membrane-bound state, we suspect that this interaction is mainly electrostatic and that penetration of the hydrophobic acyl-chain region of the bilayer is minimal. This suggests that peptide structures other than helix can significantly disrupt lipid bilayers, changing their permeability and surface area.

PGLa Structure. PGLa is less soluble in aqueous solutions than is mgn $2 \mathrm{a}$, reversibly forming a precipitate in saline at $\mathrm{pH}$ 7.4 and low temperatures that contains $\beta$-sheet and reverse turn structure. It forms a mostly unfolded structure in water

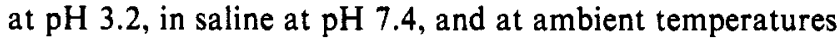
(Figure 4A; Table I). PGLa forms a $\beta$-sheet structure in water at neutral $\mathrm{pH}$, probably in an aggregated form, although these solutions are clear. Upon binding to DPPG, PGLa shows an amide I band similar to that observed for the precipitated form.
Upon binding to DMPC, the structure of PGLa becomes a $42 \pm 5 \%$ helical.

Synergistic Interaction of Mgn2a and PGLa. PGLa is only $27 \pm 5 \%$ helix when bound to DPPG, but an equimolar mixture of PGLa and mgn2a appears to contain significantly more helix when bound to DPPG than the average of the separate peptides (Table I; Figure 4B). Equimolar mixtures of PGLa and mgn2a in water do not interact in this way to form secondary structure.

One of the most striking features of these peptides is that they appear to act synergistically. To measure the membrane-perturbing activity of mgn2a and PGLa at physiologically active concentrations, we measured the release of 6carboxyfluorescein (CF) from liposomes as a function of peptide concentration and calculated constants related to membrane-perturbing activity (Figure 5). Mgn2a does not release $\mathrm{CF}$ at $10 \mu \mathrm{g} / \mathrm{mL}(3.7 \mu \mathrm{M})$. This is consistent with the low hemolytic activity of mgn2a. PGLa does release CF at relatively low concentrations. However, in the presence of $10 \mu \mathrm{g} / \mathrm{mL} \mathrm{mgn2a}$, PGLa is dramatically more active. For PGLa alone, $K_{1}$ and $K_{2}=0.16$ and $0.007(\mathrm{~s} \cdot \mathrm{M})^{-1}$, respectively. For PGLa with $3.7 \mu \mathrm{M}$ mgn2a, $K_{1}$ and $K_{2}=4.0$ and 0.3 $(\mathrm{s} \cdot \mathrm{M})^{-1}$, respectively. The change in $K_{1}$ and $K_{2}$ caused by the presence of an amount of mgn2a that by itself does not cause permeability is 25 - and 43 -fold, respectively. These results suggest that the interaction of these two antimicrobial peptides at the membrane surface produces a structure change in one or both of the peptides that potentiates the antibiotic activity.

\section{REFERENCES}

Bentz, J., \& Nir, S. (1981) J. Chem. Soc., Faraday Trans. $177,1249-1275$.

Bentz, J., Nir, S., \& Covell, D. (1988) Biophys. J. 54, 449-462.

Berman, M., \& Weiss, M. F. (1978) DHHS Publ. (NIH) No. $78-180$.

Bernard E., Faucon, J. F., Dufourcq, J., Duchesneau, L., \& Pezolet, M. (1982) Biophys. J. 37, 61-62.

Brouillette, C. G., Segrest, J. P., Ng, T., Chung, B. H., \& Ragland, J. B. (1982) Biophys. J. 37, 172-173.

Brown, L. R., Braun, W., Kumar, A., \& Wüthrich, K. (1982) Biophys. J. 37, 319-328.

Chen, H.-C., Brown, J. H., Morell, J. L., \& Huang, C. M. (1988) FEBS Lett. 236, 462-466.

Cruciani, R. A., Stanley, E. F., Zasloff, M., Lewis, D. L., \& Barker, J. L. (1988) Biophys. J. 53, 9a.

Cuervo, J. H., Rodriguez, B., \& Houghten, R. A. (1988) Pept. Res. 1, 81-86.

DeGrado, W. F., Kezdy, T. J., \& Kaiser, E. T. (1981) J. Am. Chem. Soc. 103, 679-681.

DeGrado, W. F., Musso, G. F., Lieber, M., Kaiser, E. T., \& Kézdy, F. J. (1982) Biophys. J. 37, 329-338.

Eisenberg, D. (1984) Annu. Rev. Biochem. 53, 595-623.

Gaber, B. P., \& Peticolas, W. L. (1977) Biochim. Biophys. Acta 465, 260-274.

Gaber, B. P., Yager, P., \& Peticolas, W. L. (1978) Biophys. J. 21, 161-176.

Georghiou, S., Thompson, M., \& Mukhopadhyay, A. K. (1982) Biophys. J. 37, 159-161.

Giovannini, M. G., Poulter, L., Gibson, B. W., \& Williams, D. H. (1987) Biochem. J. 243, 113-120.

Green, F. R., Lynch, B., \& Kaiser, E. T. (1987) Proc. Natl. Acad. Sci. U.S.A. 84, 8340-8344.

Guy, H. R., \& Raghunathan, G. (1988) Transport Through Membranes: Carriers, Channels, and Pumps, Jerusalem Symp. Quantum Chem. Biochem. 21, 369-379. 
Juretič, Davor, Chen, H.-C., Brown, J. H., Morell, J. L., Hendler, R. W., \& Westerhoff, H. V. (1989) FEBS Lett. 249, 219-223.

Kim, P. S., Bierzynski, A., \& Baldwin, R. L. (1982) J. Mol. Biol. 162, 187-199.

Levin, I. W., Lavialle, F., \& Mollay, C. (1982) Biophys. J. 37, 339-349.

Low, B. W., Preston, H. S., Sato, A., Rosen, L. S., Searl, J. E., Rudko, A., \& Richardson, J. S. (1976) Proc. Natl. Acad. Sci. U.S.A. 73, 2991-2994.

Marion, D., Zasloff, M., \& Bax, Ad (1988) FEBS Lett. 227, 21-26.

Matsuzaki, K., Harada, M., Handa, T., Funakoshi, S., Nobutaka, F., Yajima, H., \& Miyajima, K. (1989) Biochim. Biophys. Acta 981, 130-134.

Podo, F., Strom, R., Crifō, C., Berthet, C., Zulauf, M., \& Zaccai, G. (1982) Biophys. J. 37, 161-163.

Reeke, G. N., Jr., Becker, J. W., \& Edelman, G. M. (1975) J. Biol. Chem. 250, 1525-1547.

Soravia, E., Martini, G., \& Zasloff, M. (1988) FEBS Lett. $228,337-340$.

Sparrow, J. T., \& Gotto, A. M. (1982) CRC Crit. Rev. Biochem. 13, 87-107.

Terwilliger, T. C., Weissman, L., \& Eisenberg, D. (1982) Biophys. J. 37, 353-361.

Wallace, B. A. (1983) Biopolymers 22, 397-603.
Weinstein, J. N., Ralston, E., Leserman, L. D., Klausner, R. D., Dragsten, P., Henkart, P., \& Blumental, R. (1984) in Liposome Technology (Gregoriadis, G., Ed.) Vol. 3, pp 183-204, CRC Press, Boca Raton, FL.

Westerhoff, H. V., Juretic, D., Hendler, R. W., \& Zasloff, M. (1989a) Proc. Natl. Acad. Sci. U.S.A. 86, 6597-6601.

Westerhoff, H. V., Hendler, R. W., Zasloff, M., \& Juretić, D. (1989b) Biochim. Biophys. Acta 975, 361-369.

Williams, R. W. (1983) J. Mol. Biol. 166, 581-603.

Williams, R. W. (1986) Methods Enzymol.: Enzyme Struct. 130, 311-331.

Williams, R. W., \& Dunker, A. K. (1981) J. Mol. Biol. 152, 783-813.

Williams, R. W., Chang, A., Juretić, D., \& Loughran, S. (1987) Biochim. Biophys. Acta 916, 200-204.

Williams, R. W., Zasloff, M., \& Covell, D. (1988a) Biophys. J. 53, 631a.

Williams, R. W., Zasloff, M., \& Covell, D. (1988b) J. Cell. Biochem. Suppl. 12B, 64.

Williams, R. W., Covell, D., \& Chen, H.-C. (1988c) J. Cell. Biochem. Suppl. 13A, 96.

Zasloff, M. (1987) Proc. Natl. Acad. Sci. U.S.A. 84, 5449-5453.

Zasloff, M., Martin, B., \& Chen, H.-C. (1988) Proc. Natl. Acad. Sci. U.S.A. 85, 910-913. 